\title{
A Comparative Study of Efficiency in European Banking
}

\author{
Barbara Casu*, Philip Molyneux \\ School of Accounting, Banking and Economics, University of Wales, Bangor, LL57 2DG, UK
}

\begin{abstract}
The structure of European banking markets has substantially changed over the past decade, partially as a result of the creation of the Single Internal Market. The process of integration and accompanying deregulation has embodied an incentive for bank management to focus on improving efficiency, especially given the more competitive banking environment. In this paper, employing the non-parametric DEA approach, we investigate whether the productive efficiency of European banking systems has improved and converged towards a common European frontier between 1993 and 1997, following the process of EU legislative harmonisation. We also examine the determinants of European bank efficiency using a Tobit regression model approach. We then extend the established literature on the determinants bank efficiency by taking into account the problem of the inherent dependency of DEA efficiency scores when used in regression analysis. To overcome the dependency problem a bootstrapping technique is applied. Overall, the results suggest that since the EU's Single Market Programme there has been a small improvement in bank efficiency levels, although there is little evidence to suggest that these have converged. Efficiency differences across European banking markets appear to be mainly determined by country-specific factors.
\end{abstract}

Keywords: Efficiency, DEA, Bootstrap, European Banks.

*Corresponding author Tel:+44 1248 382643; Fax:+44 1248 364760; e-mail:abs603@ bangor.ac.uk. 


\section{Introduction}

One of the major objectives of the EU's 1992 Single Market Programme (SMP) was to facilitate the free movement of goods and services across Member States and to improve economic efficiency. As a 1996 European Commission survey noted: "Although it is still too early for many Single Market measures to have taken full effect, there is evidence of positive, albeit preliminary effects of the Single Market in triggering the expected reinforcement of integration, competition, economic performance and benefits for the consumers" [Communication from the Commission to the European Parliament and Council (1996)].

An integral part of the SMP was directed at harmonising regulations and fostering competition in the banking sector. Up until the mid-1980's there had been little progress in removing barriers to trade in financial services. Typically, European banking systems were characterised by relatively high levels of government controls and restrictions that inhibited competition and maintained a protected banking environment. Interest rate restrictions and capital controls were widespread, and branching restrictions existed in some countries. There were marked differences across banking systems: for instance, the United Kingdom, Germany, Denmark and the Netherlands had rather liberal and open banking markets, while regulatory restrictions limited the competitive environment in the remaining EU Member Countries [see European Commission (1997)].

The EC's 1985 White Paper [Commission of the European Communities (1985)] on the completion of the Single Market and its incorporation in the Single European Act of February 1986 constituted an important and renewed commitment by the European Commission towards the liberalisation of the EU banking market. This culminated in the Second Banking Co-ordination Directive, adopted in 1989, together with the two parallel Directives on Solvency Ratios and Own Funds. This formed a comprehensive framework for regulating all the banking business in the EU. By 1 January 1993 the aforementioned 
legislation had created the 'largest and most open banking market in the world' by eliminating or lessening existing barriers and by establishing minimum regulatory requirements across EU banking systems.

This paper investigates whether the productive efficiency of European banking systems has improved since the creation of the Single Internal Market. We examine the European banking markets between 1993 and 1997 using the non-parametric DEA approach; the aim is to investigate whether there has been an increase and convergence of efficiency levels following the process of legislative harmonisation. We also evaluate the determinants of European bank efficiency by using the Tobit regression model approach in order to analyse the influence of various country-specific and environmental factors on bank efficiency. To overcome the problem of inherent dependency of DEA efficiency scores when used in regression analysis we apply a bootstrapping technique.

The paper is set out as follows: Section 2 illustrates the methodological approach followed in the empirical analysis; Section 3 describes the sample; Section 4 reports the results and the final section is the conclusions.

\section{Methodological Issues}

The approach to frontier estimation proposed by Farrell (1957) was not given much detailed empirical attention for about two decades, until a paper by Charnes, Cooper and Rhodes (CCR) in 1978, in which the term Data Envelopment Analysis was first used. Since then there has been a large number of papers which have applied and extended the methodology ${ }^{1}$. Data Envelopment Analysis (DEA) is a mathematical programming approach for the construction of production frontiers and the measurement of efficiency relative to the constructed frontiers. DEA is based on a concept of efficiency very similar to the

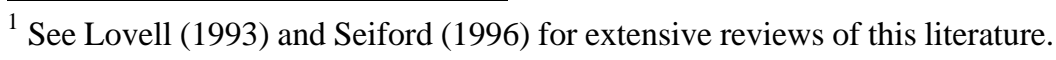


microeconomic one; the main difference is that the DEA production frontier is not determined by some specific functional form, but it is generated from the actual data for the evaluated firms. In other words, the DEA frontier is formed as the piecewise linear combination that connects the set of 'best-practice observations' in the data set under analysis, yielding a convex Production Possibility Set (PPS). As a consequence, the DEA efficiency score for a specific Decision-Making Unit (DMU) is not defined by an absolute standard, but it is defined relative to the other DMUs in the specific data set under consideration. This feature differentiates DEA from the parametric approaches, which require a specific pre-specified functional form of the modelled production or cost function.

In their original paper, Charnes, Cooper and Rhodes (1978) proposed a model that had an input orientation and assumed constant returns to scale (CRS). Later studies have considered alternative sets of assumptions. The assumption of variable returns to scale (VRS) was first introduced by Banker, Charnes and Cooper (1984). The CRS assumption is only appropriate when all DMUs are operating at an optimal scale. However, factors like imperfect competition and constraints on finance may cause a DMU not to be operating at optimal scale. As a result, the use of the CRS specification when some DMUs are not operating at optimal scale will result in measures of technical efficiency (TE) which are confounded by scale efficiencies (SE).

The VRS linear programming problem can be defined as:

$$
\min _{\theta, \lambda} \theta
$$

$$
\begin{gathered}
\text { st }-y_{i}+Y \lambda \geq 0 \\
\theta x_{i}-X \lambda \geq 0 \\
N 1^{\prime} \lambda=1 \\
\lambda \geq 0
\end{gathered}
$$


where $\mathrm{N} 1$ is an $\mathrm{Nx} 1$ vector of ones.

This approach forms a convex hull of intersecting planes which envelope the data points more tightly than the CRS conical hull and thus provide technical efficiency scores that are greater than or equal to those obtained using the CRS model. The VRS specification has been the most commonly used specification in the 1990's [see Coelli et al. (1998)].

In the input-orientated models, the DEA method seeks to identify technical inefficiency as a proportional reduction in input usage. It is also possible to measure technical inefficiency as a proportional increase in output production. These two measures provide the same value under CRS, but do not equate when VRS is assumed. The choice of orientation has both practical and theoretical implications. In some applications, the choice of the orientation is clear; for example, in industries where the emphasis is on cost-control, the 'natural' choice would be an input-orientation [Ferrier and Valdmanis (1996)].

Many studies have tended to select input-orientated measures because the input quantities appear to be the primary decision variables, although this argument may not be valid in all industries. However, some research has pointed out that restricting attention to a particular orientation may neglect major sources of technical efficiency in the other direction [Berger et al. (1993)]. To date, the theoretical literature is inconclusive as to the best choice among the alternative orientations of measurement.

It is necessary to point out that output- and input-orientated models will estimate exactly the same frontier and, therefore, by definition, identify the same set of efficient DMUs. It is only the efficiency measures associated with the inefficient DMUs that may differ between the two methods.

Although the basic DEA models (CRS and VRS) have been improved in a number of ways in recent years [see Lovell (1993) and Seiford (1996)], one of the main criticisms faced by researchers using non-parametric methods is the difficulty of drawing statistical inference. 
The more recent literature, however, has been fairly successful in finding ways to overcome this problem [see Grosskopf (1996)]. One of the first tools employed to this end was regression analysis. The basic idea of what has become known as the "Two-Step" procedure is to treat the efficiency scores as data or indices and use linear regression to explain the variation of these efficiency scores. The first improvement to this model has come with the attempt to account for the fact that efficiency scores are censored [Lovell, Walters and Wood (1995)]; as a result, a model that accounted for the fact that the dependent variable was limited became preferred to OLS.

An important conceptual issue relates to the data-generating process and the associated issue of distribution of the error terms. Put simply, if the variables used in specifying the original efficiency are correlated with the explanatory variables used in the second stage, then the second stage estimates will be inconsistent and biased [Deprins and Simar (1989); Simar, Lovell and Vanden Eeckaut (1994)].

Another criticism that is sometimes levelled against this approach is that it only considers radial inefficiency and ignores the slacks. A possible solution to this has been proposed by Fried, Schmidt and Yaisawarng (1995) and involves estimating a SUR (Seemingly Unrelated Regression) system of equations for the slacks. Bhattacharyya et al. (1997) pointed out that when employing regression analysis in the second step to explain the variation of the efficiency scores, it is likely that the included explanatory variables fail to explain the entire variation in the calculated efficiencies and the unexplained variation mixes with the regression residuals, adversely affecting statistical inference. They propose the use of a stochastic frontier regression model, which allows for the decomposition of the variation of the calculated efficiencies into a systematic component and a random component.

In this study, the basic DEA model will be extended to take into account environmental variables. In this context, the term environment is used to describe factors that 
could influence the efficiency of a firm, where such factors are not traditional inputs and are not under the control of management [Fried et al. (1995)]. Such factors can include, for example, ownership differences (public/private), location characteristics and government regulations. There are a number of ways in which such factors can be accommodated in DEA analysis $^{2}$; following Coelli et al. (1998) we adopt the so-called Two-Step approach.

This approach involves solving a DEA problem in a first stage analysis, involving only the traditional inputs and outputs. In the second stage, the efficiency scores from the first stage are regressed upon environmental variables. The sign of the coefficients of the environmental variables indicate the direction of the influence, and standard hypothesis testing can be used to assess the strength of the relationship. This method, which can accommodate both continuous and categorical variables, is conducted by using Tobit regression model because it can account for truncated data.

A new conceptual issue has recently been raised by Xue and Harker (1999): they point out that efficiency scores generated by DEA models are clearly dependent on each other in the statistical sense. The reason for dependency is the well-known fact that the DEA efficiency score is a relative efficiency index, not an absolute efficiency index. Because of the presence of the inherent dependency among efficiency scores, one basic model assumption required by regression analysis, independence within the sample, is violated. As a result, the conventional procedure, followed in the literature, is invalid. They propose a bootstrap method to overcome this problem.

The bootstrap is a computer-based method for assigning measures of accuracy to statistical estimates. It was first introduced by Efron (1979) and since then it has become a popular and powerful statistical tool. Simar (1992) was possibly the first to introduce the bootstrap method for computing confidence intervals for efficiency scores derived from non-

\footnotetext{
${ }^{2}$ See Rouse (1996) for a survey of alternative approaches to the treatment of environmental factors in DEA.
} 
parametric frontier methods. Since then, it has been used to provide an empirical distribution of efficiency scores for each observation in the sample [Atkinson and Wilson (1995)]; to derive the confidence intervals and a measure of bias for DEA efficiency scores [Ferrier and Hirschberg (1995)]; and to analyse the sensitivity of efficiency scores to the sampling variations of the estimated frontier [Simar and Wilson (1995)].

To summarise, the literature to date has concentrated mainly on estimating the distribution of efficiency scores. Xue and Harker (1999), as far as we are aware, are the first to address the problem of the inherent dependency ${ }^{3}$ of efficiency scores when used in regression analysis. They present the following procedure for the regression analysis of the DEA efficiency scores by using the bootstrap method to solve the dependency problem:

- Step 1: Construct the sample probability distribution $\hat{F}$ by assigning probability of $1 / n$ at each DMU in the observed sample $\left(x_{1}, x_{2}, \ldots, x_{n}\right)$.

- Step 2: Draw $c$ (c is a constant) random samples of size $n$ with replacement from the original sample $\left(x_{1}, x_{2}, \ldots, x_{n}\right)$ :

$$
S_{k}=\left(x_{k 1}, x_{k 2}, \ldots x_{k n}\right), \quad k=1,2, \ldots c
$$

where $x_{k i}=\left(u_{k i}, v_{k i}\right), \mathrm{i}=1,2, \ldots . \mathrm{n} . S_{k}$ is the so-called bootstrap sample.

- Step 3: for each bootstrap sample $S_{k}, k=1,2, \ldots c$, run the DEA model and recalculate the efficiency scores for all $n$ DMUs:

$$
\theta_{k i}=\phi_{i}\left(u_{k}\right), \quad i=1,2, \ldots \mathrm{n},
$$

\footnotetext{
${ }^{3}$ In regression analysis, if the response variables $Y_{1}, Y_{2}, \ldots, Y_{n}$ are dependent on each other, or correlated, when we fit the regression model as if they were not correlated, the estimate of the standard error of the regression coefficient estimate, $\hat{s} e\left(\hat{\beta}_{j}\right)$, which is obtained by fitting the regression model, is no longer correct. As a consequence, the t-ratios and P-values for the Hypothesis Tests are no longer correct. Therefore, the conclusions reached through this kind of direct regression analysis may be misleading (Xue and Harker, 1999).
} 
- Step 4: for each bootstrap sample $S_{k}, k=1,2, \ldots c$, evaluate the bootstrap replication $\hat{\beta}_{k j}, \mathrm{k}=1,2, \ldots c, j=0,1, . ., m$, by fitting the regression model:

$$
\theta_{k i}=G\left(\beta_{k}, v_{k i}\right)+\varepsilon_{k i}, i=1,2, \ldots n, \quad \beta_{k}=\left(\beta_{k 0}, \beta_{k 1}, \ldots, \beta_{k j}, \ldots, \beta_{k m}\right)
$$

- Step 5: Estimate the standard error $s e\left(\hat{\beta}_{j}\right)$ by the sample standard deviation of the $c$ bootstrap replications of $\hat{\beta_{j}}$ :

$$
\hat{s} e_{c}\left(\hat{\beta}_{j}\right)=\left\{\sum_{k=1}^{c}\left(\beta_{k j} \hat{-} \overline{\beta_{j}}\right)^{2} /(c-1)\right\}^{1 / 2}, j=1,2, \ldots, m
$$

where

$$
\overline{\beta_{j}}=\frac{\sum_{k=1}^{c} \hat{\beta_{k j}}}{c}, \quad j=1,2, \ldots, m
$$

We call $\hat{s} e_{c}\left(\hat{\beta}_{j}\right)$ the bootstrap estimator for the standard error of $\hat{\beta}_{j}$.

Now we are ready to use a $t$-test to test the following hypothesis:

$$
H_{0}: \beta_{j}=0, \quad \text { vs. } \quad H_{1}: \beta_{j} \neq 0 \text {. }
$$

Calculate the test statistic according to:

$$
t=\frac{\hat{\beta}_{j}}{\operatorname{se}_{c}\left(\hat{\beta}_{j}\right)}
$$


and compare $t$ to the critical value $t_{\alpha / 2}$ from the Student $t$ distribution with degrees of freedom equal to $(n-m-1)$. According to its authors, the above procedure, unlike ordinary regression, correctly implement Efron's bootstrap to give appropriate standard errors when the $n$ original DMUs $X_{i} i=1,2, \ldots n$, are independently sampled from $F$, even though the efficiency scores computed from the $X$ 's are dependent.

In this study, in order to minimise the bias arising from the inherent dependency problem, we substitute the conventional estimators of the Tobit regression coefficient estimates with the bootstrap estimators to calculate the standard errors of these estimates.

\section{Data and Variables}

\subsection{Definition of the Sample and Data Sources}

The geographical coverage of this study is as follows: France, Germany, Italy, Spain and the United Kingdom. The choice of the above countries is based as much on their relative economic weight inside the EU as on the size of their respective banking sectors ${ }^{4}$. The time span considered is from 1993 to 1997; that is following the implementation of the Single Market Program (SMP).

A sample of 750 banks from the above countries (the largest 150 banks by asset size in each respective country) was drawn from the London-based International Bank Credit Analysis LTD's 'Bankscope' database. We then excluded the subsidiaries of foreign banks, the specialised financial institutions and the central institutions. Furthermore, given the need for comparable data from different countries, all banks particular to a certain country (for

\footnotetext{
${ }^{4}$ In 1998, the total assets of the banking sectors of France, Germany, Italy, Spain and the UK amounted to 16,530 billion USD, representing nearly $80 \%$ of the total assets of the banking sectors of the European Union as a whole (20,717 USD)(Banca d'Italia, Annual Report, 1998).
} 
example, special credit institutions in Italy, finance companies in France and official credit institutions in Spain) were removed from our sample. The result is a pooled sample of 530 banks. The data were extracted from non-consolidated income statement and balance sheet data corresponding to the years 1993-97. All data are reported in ECU as the reference currency; they are in real 1997 terms and have been converted using individual country GDP deflators $^{5}$. Table 1 shows some descriptive statistics of the sample. Differences in the average size of banks are substantial (the average total assets size of UK banks is more than double that of Italian banks and nearly four times that of Spanish banks). Moreover, the average size of commercial banks is nearly five times bigger than that of their savings bank, co-operative bank and real estate bank counterparts. These large discrepancies across countries can be thought of reflecting the legacy of different banking regulations [Dietsch and Weill (1998)].

\section{INSERT TABLE 1}

\subsection{Input and Output Definition}

In the present international setting, the need for comparable data from different countries imposes strong restrictions on the type of variables one is able to use, not least because of the various accounting criteria used in the five countries under investigation. To minimise possible bias arising from different accounting practices we have chosen broad variable definitions as presented by IBCA Bankscope ${ }^{6}$.

\footnotetext{
${ }^{5}$ To convert values in local currencies into a common currency we may use either the official exchange rate or the purchasing power parity (PPP) rate as computed by the OECD; the two approaches seem to yield to very similar results [Berg (1993)].

${ }^{6}$ Pastor, Pérez and Quesada (1995) followed the same approach.
} 
Even today, there is no all-encompassing theory of the banking firm and no agreement on the explicit definition and measurement of banks' inputs and outputs ${ }^{7}$. Berger and Humphrey (1997) pointed out that, although there is no 'perfect approach', the intermediation approach may be more appropriate for evaluating entire financial institutions because this approach is inclusive of interest expenses, which often account for one-half to two-thirds of total costs. Moreover, the intermediation approach may be superior for evaluating the importance of frontier efficiency to the profitability of financial institutions, since the minimisation of total costs, not just production costs, is needed to maximise profits. Following the modern empirical literature [see, among others, Molyneux et al. (1996); Mester (1996)], we use the intermediation approach, which views financial institutions as mediators between the supply and the demand of funds. The main consequence of the intermediation approach is that deposits are considered as inputs, and interest on deposits is a component of total costs, together with labour and capital costs ${ }^{8}$. Accordingly, in this study we specify two outputs: $\mathrm{y}=$ total loans, $\mathrm{y}_{2}=$ other earning assets; and two inputs: $\mathrm{x}=$ total costs (interest expenses, non-interest expenses, personnel expenses), $\mathbf{x}=$ total customers and short term funding (total deposits).

\footnotetext{
${ }^{7}$ One of the main problem faced by researchers investigating banks' cost efficiency relates to difficulties in the definition and measurement of the concept of bank output, mainly as a result of the nature and functions of financial intermediaries. The most debated issue regards the role of deposits: on one hand, it is argued that they are an input to the production process (intermediation and asset approach); on the other hand, it is suggested that deposits are an output (production approach), involving the creation of value added, and for which customers bear an opportunity cost (value added approach, user cost approach).

8 Under the non-parametric approach which will be implemented in our empirical analysis, increasing the number of variables reduces the number of technically inefficient observations [see Coelli et al. (1998)]. Therefore, in order to minimise this possible drawback of the methodology, we restricted our choice of variables to a two-input, two-output model.
} 


\subsection{Environmental Variables}

To further investigate the determinants of European bank efficiency we follow the socalled Two-Step approach, as suggested by Coelli et al. (1998). Using the efficiency measures derived from the DEA estimations as the dependent variable, we then estimate the following Tobit regression model ${ }^{9}$ :

$\theta_{i}=\beta_{1} F R A+\beta_{2} G E R+\beta_{3} I T A+\beta_{4} S P A+\beta_{5} U K+\beta_{6} E T A+\beta_{7} R O A E+\beta_{8} C O M M+\beta_{9} Q U O T+\varepsilon_{i}(8)$ where:

1. FRA, GER, ITA, SPA and UK are dummy variables indicating the country of origin of the bank (= 1 if based in the country; = 0 otherwise);

2. ETA: Equity/Total Assets;

3. ROAE: Return on Average Equity;

4. $\mathrm{COMM}=1$ if a commercial bank; $=0$ otherwise;

5. QUOT $=1$ if the bank is listed on the Stock Exchange; $=0$ otherwise.

Country dummies (FRA, GER, ITA, SPA and UK) are used to distinguish between the country of origin of the banks in the sample. We then use the average capital and profitability ratios. The average capital ratio is measured by equity over total assets (E/TA) while the profitability ratio is defined as the Return on Average Equity (ROAE). In the empirical literature, other studies [see Mester (1996); Pastor et al. (1997); Carbo et al. (1999)] have found positive relationships both between ROE and efficiency (i.e., the larger the profits, the higher the efficiency) and between E/TA and efficiency (i.e. lower E/TA leads to lower efficiency levels, because lower equity ratios imply a higher risk-taking propensity and greater leverage, which could result in greater borrowing costs). We introduce the dummy 
variable COMM in order to detect whether there are efficiency differences between commercial banks and other types of banks (such as savings and co-operative banks). Finally, the dummy variable QUOT is included to distinguish between quoted and non-quoted banks.

To test for differences between the country dummy coefficients, we test the null hypothesis $H_{0}: \beta_{1}=\beta_{2}=\beta_{3}=\beta_{4}=\beta_{5}$ against the alternative hypothesis $\left(H_{1}\right)$ that one pair at least is unequal in each year. Finally, in order to investigate possible determinants of bank efficiency, we test the following hypothesis at $\alpha=0.05$ significance level: $H_{0}: \beta_{6,7,8,9}=0$ vs. $H_{1}: \beta_{6,7,8,9} \neq 0$.

\section{Empirical Results}

\subsection{DEA Efficiency Estimation}

This section reports the results of the DEA efficiency analysis ${ }^{10}$ relative to the European common frontier. We first define the common frontier following the traditional approach, i.e. building the EU frontier by pooling the data set for the banks in all five countries in the sample ${ }^{11}$. This allows us to compare the banks of each country against the same benchmark.

\footnotetext{
${ }^{9}$ The Tobit regression analysis is computed in Limdep 7.0.

10 The linear programming problems are solved by using the DEAP Version 2.1 Computer Program, by Tim Coelli. The terminology adopted is the standard terminology, as can be found in Charnes et al. (1978).

${ }^{11}$ It is important to remember that the sample comprises the largest banks in each country and that the number of banks composing the sample changes in different years, to allow us to investigate the impact on cost efficiency of the restructuring process that has taken place in the five European countries during the time of analysis.
} 
Table 2 below illustrates the average efficiency scores relative to the whole sample ${ }^{12}$.

\section{INSERT TABLE 2}

Overall, the results show relatively low average efficiency scores; nevertheless, it is possible to detect a slight improvement in the efficiency levels through time $(+6.3 \%$ according to the input-based approach and $+6.6 \%$ according to the output-based approach, between 1993 and 1997) ${ }^{13}$. Figure 1 below illustrates the frequency distribution of average efficiency scores over the period of analysis. The majority of DMUs comprising the sample seem to cluster around levels of efficiency of around 0.65. This is the same range as those found in other recent studies on European bank efficiency using DEA [for example, Berg et al. (1993) found overall average efficiency of 0.58 for Finland, 0.78 for Norway and 0.89 for Sweden; European Commission (1997) found average efficiency levels in the EU of 0.73; Pastor et al. (1997) report average efficiency levels equal to 0.79 and Dietsch and Weill (1998) found average efficiency levels in the EU of 0.64 in 1996].

\section{INSERT FIGURE 1}

\footnotetext{
$\overline{12}$ In order to check that the results are not too sensitive to the presence of outliers, we followed a procedure used, among others, by Resti (1997). After solving the DEA problems using all the observations composing the sample, all banks presenting an efficiency score equal to unity were deleted and DEA problems were solved once more on the new sample. The correlation between the efficiency scores obtained on the original sample and on the reduced sample is an indicator of the robustness of the results. The Pearson correlation coefficient and the Spearman rank correlation coefficient were then estimated to detect the sensitivity to outliers and the results were satisfactory.

13 The non-parametric Mann-Whitney test was used for testing the null hypothesis that the central locations of the two populations are the same against the one-sided alternative that the central location of the 1993 efficiency scores is lower than that of 1997: according to the results of the test, the null hypothesis is to be rejected at $99 \%$ confidence interval.
} 
It is of interest to analyse the relative position of each country on the European common frontier. These results are summarised in Table 3 and in Figure 2: it is possible to detect an improvement in the average efficiency scores for almost all countries in the sample over the period of analysis, with the exception of Italy, which records a slight decrease ($0.5 \%$ over the period). In particular, bank efficiency levels in Spain seem to have improved the most $(+11 \%$ over the period) followed by the UK $(+9.4 \%)$ and France $(+4.6 \%)$. Overall, the results show that the efficiency gap among countries grew wider over the period [in 1993, the difference between the banking system showing the higher efficiency levels (UK) and the one showing the lowest (Spain) was 19.1\% while in 1997, the difference in efficiency levels between the UK and Italy was equal to $26.6 \%]$.

\section{INSERT TABLE 3}

\section{INSERT FIGURE 2}

Table 4 illustrates the composition of the European efficient frontier. It is worth remembering that in DEA methodology the efficient frontier is generated by the input/output combination of the 'best-practice' units, i.e. by those DMUs which achieved an efficiency score of unity. In other words, DEA establishes a 'benchmark' efficiency score of unity that no individual firm can exceed. This benchmark is a linear combination of efficient banks in a sample, which constitute the reference technology for the sample.

\section{INSERT TABLE 4}

It is possible to note that the influence of the banks of each country changes slightly, with the importance of French banks in building the frontier decreasing in favour of British banks. The aforementioned results seem to suggest that, even though it is possible to detect a slight improvement in the overall efficiency scores, there are marked differences in bank 
efficiency levels across EU countries. This seems to be in accordance with the assumption that country-specific characteristics still play an important part in the explanation of bank efficiency levels.

\subsection{Determinants of Bank Efficiency}

To examine the determinants of bank efficiency, we estimate the Tobit regression described in equation (8). The results of the Tobit regression for 1997 are summarised in table $5^{14}$ :

\section{INSERT TABLE 5}

The coefficients $\beta_{1}, \beta_{2}, \beta_{3}, \beta_{4}, \beta_{5}$ of the dummy variables (FRA, GER, ITA, SPA and UK) represent the intercepts for the five banking systems under study. In order to test the influence of the geographical location, we tested the null hypothesis $H_{0}: \beta_{1}=\beta_{2}=\beta_{3}=\beta_{4}=\beta_{5}$ against the alternative hypothesis $\left(H_{1}\right)$ that one pair at least is unequal in each year. The results of the F-test allowed us to reject the null hypothesis every year $^{15}$.

The results for 1997 note that although there is a positive sign on the (E/TA) variable it is not statistically significant at the $5 \%$ level. (In fact, we only find the equity ratio to have a positive statistically significant relation to efficiency in our 1996 estimates). As such, there does not appear to be a strong relationship between variation in bank equity and efficiency levels. In contrast, ROAE is positively related to bank efficiency; in our 1997 estimates profitable banks appear more efficient. However, this relationship is only found to hold in one other year (1995). The results also suggest that commercial banks are no more efficient

\footnotetext{
${ }^{14}$ Results for 1993-1996 are reported in the Appendix.

${ }^{15}$ F-test $\left(\mathrm{df}_{1}=4 ; \mathrm{df}_{2}=374\right): 1993=4730.862 ; 1994=1588.623 ; 1995=1682.859 ; 1996=4730.246 ; 1997=$ 2640.862.
} 
than their savings and co-operative bank counterparts. The positive and statistically significant sign on the QUOT variable (a relationship found in all our yearly estimates) indicates that listed banks are more efficient than their non-listed counterparts.

However confident we may feel about these results, we need to take into account the problem of the inherent dependency of efficiency scores when used in regression analysis. To recall, the reason for dependency is the well-known fact that the DEA efficiency score is a relative efficiency index. Because of the presence of the inherent dependency among the efficiency scores, one basic model assumption required by regression analysis, independence within the sample, is violated. As noted by Xue and Harker (1999), the conventional procedure, as outlined so far in this paper, may be inappropriate and the results could be misleading. In an attempt to overcome this problem, we apply a bootstrapping technique.

\subsection{The Bootstrapping Procedure ${ }^{16}$}

Following Xue and Harker (1999), the bootstrap method is implemented as follows:

- Construct the sample probability distribution $\hat{F}$, assigning probability of $1 / 379$ at each DMU in the observed sample ${ }^{17}$.

- Take $\mathrm{c}=1000$ random samples of size 379 with replacement from the observed sample of 379 European banks. These samples are the bootstrap samples.

- Compute the DEA efficiency scores for each bootstrap sample.

- Within each bootstrap sample, fit the following regression model:

\footnotetext{
${ }^{16}$ The computer routine to perform the described procedure has been written by C. Verdes, University of AL I CUZA, Iasi, Romania - SEES, University of Wales, Bangor.

${ }^{17}$ To complete this exercise, we considered a balanced sample on a pooled European basis.
} 


$$
\begin{aligned}
& \hat{\theta}_{k i}=\hat{\beta}_{k 1} F R A+\hat{\beta}_{k 2} G E R+\hat{\beta}_{k 3} I T A+\hat{\beta}_{k 4} S P A+\hat{\beta}_{k 5} U K+ \\
& +\hat{\beta}_{k 6} E T A_{k i}+\hat{\beta}_{k 7} R O A E_{k i}+\hat{\beta}_{k 8} C O M M_{k i}+\hat{\beta}_{k 9} Q U O T_{k i}+\varepsilon_{k i}
\end{aligned}
$$

for $\mathrm{i}=1,2, \ldots, 379 ; \mathrm{k}=1,2, \ldots, 1000$.

Here $\theta_{k i}$ is the DEA efficiency score for DMU $i$ in bootstrap sample $k$ and $\hat{\beta}_{k j}(j=1, \ldots 9)$ are

the bootstrap replications for $\hat{\beta}_{j}$ in bootstrap sample $\mathrm{k}$.

- Estimate the standard error $\operatorname{se}\left(\hat{\beta}_{j}\right)$ by the sample standard deviation of the $c$ bootstrap replications of $\hat{\beta}_{j}$ [see equation (5)].

where

$$
\overline{\beta_{j}}=\frac{\sum_{k=1}^{c} \hat{\beta_{k j}}}{c}, \quad j=1,2, \ldots, 9 \quad c=1000
$$

- Calculate the $t$-statistic according to equation (7) and then test the individual hypothesis $H_{0}: \beta_{j}=0$ against the two-sided alternative $H_{0}: \beta_{j} \neq 0$ at $\alpha=0.05$ significant level.

The results of the bootstrapping procedure for 1997 are shown in table $6^{18}$.

\section{INSERT TABLE 6}

Comparing the results of the bootstrap regression to the results of the direct Tobit regression, the first conclusion we can draw is that the bootstrap method helps us to reduce the ambiguity of the responses of the hypothesis testing. In fact, while the coefficients

\footnotetext{
${ }^{18}$ Results for the years 1993-1996 are reported in the Appendix.
} 
$\beta_{1}, \beta_{2}, \beta_{3} \beta_{4}, \beta_{5}$ lead us to the same conclusions reached earlier ${ }^{19}$ (i.e. the geographic location does influence average efficiency levels), we do not find sufficient evidence to reject the hypothesis that the average capital ratio (E/TA) and the Return on Average Equity (ROAE) do not influence bank efficiency levels. These results, which contrast with the positive relationship between both ROAE and E/TA and efficiency levels found in previous studies [see Mester (1996); Pastor et al. (1997); Carbo et al. (1999)] and the positive statistically significant relationship between ROAE and efficiency presented in some of our earlier analysis, seem to suggest that inference on the determinants of bank efficiency drawn from non-bootstrapped regression analysis may be biased and misleading. Note also that in the bootstrap estimates the QUOT dummy is found to be statistically significant at the $5 \%$ level in 1993, 1995 and 1996, compared with the conventional Tobit, where QUOT was statistically significant in all years under study. (The COMM dummy was statistically significant for all years using both the conventional and the bootstrap estimations). Overall, both the bootstrap and the conventional Tobit results presented in this paper suggest that most of the efficiency differences found across European banking systems are due country-specific aspects of the banking technology. This can be thought of as reflecting both the legacy of different banking regulations and the different managerial strategies implemented to face up to the new challenges brought about by information technology, financial innovation and greater competition within the European banking market. These results, to a certain extent, confirm previous findings ${ }^{20}$ and lead us to conclude that country-specific factors are still important determinants in explaining differences in bank efficiency levels across Europe.

\footnotetext{
$\overline{19}$ Results of the Ftest allow us to reject the null hypothesis $H_{0}: \beta_{1}=\beta_{2}=\beta_{3}=\beta_{4}=\beta_{5}$ against the alternative hypothesis $\left(H_{1}\right)$ that one pair at least is unequal in each year.

${ }^{20}$ For example, Pastor et al. (1997) conclude that the country-specific environmental factors exercise a strong influence over the average efficiency score of each country.
} 
This suggests that the EU's SMP has not had a major influence in promoting a convergence of bank efficiency levels.

\section{Conclusions}

This paper investigates whether there has been an improvement and convergence of productive efficiency across European banking markets since the creation of the Single Internal Market. A non-parametric approach, in the form of Data Envelopment Analysis (DEA) was applied. Using efficiency measures derived from DEA estimation we also evaluate the determinants of European bank efficiency using the Tobit regression model approach. We then extend the established literature on modelling the determinants of bank efficiency by recognising the problem of the inherent dependency of DEA efficiency scores when used in regression analysis. To overcome the dependency problem, we follow the approach suggested by Xue and Harker (1999) and apply a bootstrapping technique to our Tobit regression analysis.

Overall, the DEA results show relatively low average efficiency levels; nevertheless, it is possible to detect a slight improvement in the average efficiency scores over the period of analysis for almost all banking systems in the sample, with the exception of Italy. However, the results show that the efficiency gap among countries grew even wider over the period $1993-1997$.

An important outcome of this analysis lies with the results provided by the bootstrap regression, which indicate that that the geographic location has the most important influence on average bank efficiency scores in every year. We found lttle evidence to suggest that the average capital ratio (E/TA) and the Return on Average Equity (ROAE) explain variations in bank efficiency levels. These results contrast with the positive relationship between both ROAE and E/TA and efficiency levels found in previous studies. This perhaps suggests that 
inference on the determinants of bank efficiency drawn from non-bootstrapped regression analysis may be biased and misleading. Overall, both the bootstrap and the conventional Tobit results presented in this paper suggest that most of the efficiency differences found across European banking systems are due country-specific aspects of the banking technology. This can be thought of as reflecting both the legacy of different banking regulations and the different managerial strategies implemented to face up to the new challenges brought about by information technology, financial innovation and greater competition within the European banking market. These results, to a certain extent, confirm previous findings and lead us to conclude that country-specific factors are still important determinants in explaining differences in bank efficiency levels across Europe. This suggests that the EU's SMP has not had a major influence in promoting a convergence of bank efficiency levels.

\section{Acknowledgements}

Thanks to Professor E.P.M Gardener for his comments on earlier versions of the paper. We are greatly indebted to $\mathrm{C}$. Verdes for his help in writing the bootstrapping computer routine. We also wish to thank M. Brown, C. Girardone and J. Williams for their valuable suggestions. 


\section{Appendix}

6.1 Tobit Censored Regression Estimates

\begin{tabular}{|c|c|c|c|c|}
\hline 1993 & $\hat{\beta}_{j}$ & Std. Error & t value & $\overline{\operatorname{Pr}}(>|t|)$ \\
\hline FRA & .628416 & .018059 & 34.798 & .0000 \\
\hline GER & .740559 & .015776 & 46.942 & .0000 \\
\hline ITA & .565592 & .024866 & 22.745 & .0000 \\
\hline SPA & .529152 & .021563 & 24.539 & .0000 \\
\hline UK & .757705 & .021366 & 35.464 & .0000 \\
\hline ETA & .0000333 & .0025217 & .013 & .9895 \\
\hline ROAE & .0005445 & .0003128 & 1.740 & 0.0818 \\
\hline COMM & .0020804 & .0149369 & .139 & .8892 \\
\hline QUOT & .0647023 & .0185407 & 3.490 & .0005 \\
\hline \multicolumn{5}{|l|}{1994} \\
\hline FRA & .722489 & .0113681 & 52.8085 & .0000 \\
\hline GER & .785564 & .011820 & 67.3038 & .0000 \\
\hline ITA & .644545 & .018974 & 33.9692 & .0000 \\
\hline SPA & .654217 & .016146 & 40.5185 & .0000 \\
\hline UK & .785788 & .016326 & 48.1301 & .0000 \\
\hline ETA & $.132317 \mathrm{E}-02$ & $.184337 \mathrm{E}-02$ & .717801 & .4729 \\
\hline ROAE & $.295890 \mathrm{E}-03$ & $.326345 \mathrm{E}-03$ & .906678 & .3646 \\
\hline COMM & $.531899 \mathrm{E}-02$ & .011247 & .472934 & .6363 \\
\hline QUOT & .30135 & .013720 & 2.19645 & .0281 \\
\hline \multicolumn{5}{|l|}{1995} \\
\hline $\begin{array}{l}\text { FRA } \\
\end{array}$ & .643098 & .017291 & 37.1920 & .0000 \\
\hline GER & .754802 & .014508 & 52.0265 & .0000 \\
\hline ITA & .555382 & .022040 & 25.1992 & .0000 \\
\hline SPA & .585460 & .020944 & 27.9531 & .0000 \\
\hline UK & .731742 & .019778 & 36.9972 & .0000 \\
\hline ETA & $-203572 \mathrm{E}-02$ & $.220280 \mathrm{E}-02$ & -.924154 & .3554 \\
\hline ROAE & $.131381 \mathrm{E}-02$ & $.636268 \mathrm{E}-03$ & 2.06587 & .0389 \\
\hline COMM & $-.33813 \mathrm{E}-02$ & .012845 & -.263234 & .7924 \\
\hline QUOT & .058225 & .015857 & 3.67186 & .0002 \\
\hline \multicolumn{5}{|l|}{1996} \\
\hline "FRA & (610190 & .014786 & 41.2684 & 2.0000 \\
\hline GER & .719010 & .012675 & 56.7248 & .0000 \\
\hline ITA & .481954 & .017506 & 27.5314 & .0000 \\
\hline SPA & .518734 & .017213 & 30.1356 & .0000 \\
\hline UK & .783748 & .016999 & 46.1043 & .0000 \\
\hline ETA & $.562716 \mathrm{E}-02$ & $.145072 \mathrm{E}-02$ & 3.87887 & .0001 \\
\hline ROAE & $-.11383 \mathrm{E}-03$ & .399853E-03 & -.284687 & .7759 \\
\hline COMM & $.469199 \mathrm{E}-02$ & .013359 & .351225 & .7254 \\
\hline QUOT & .053910 & .016660 & 3.23599 & .0012 \\
\hline
\end{tabular}




\subsection{Bootstrap Tobit Censored Regression Estimates}

\begin{tabular}{|c|c|c|c|c|}
\hline 1993 & $\hat{\beta}_{j}$ & $\overline{\beta_{j}}$ & $\hat{s} e_{1000}\left(\hat{\beta}{ }_{j}\right.$ & t value \\
\hline FRA & .628416 & .676553 & .052819 & 11.89753 \\
\hline GER & .740559 & .776139 & .033371 & 22.19168 \\
\hline ITA & .565592 & .609849 & .050313 & 11.24147 \\
\hline SPA & .529152 & .571722 & .047938 & 11.03825 \\
\hline UK & .757705 & .788606 & .029285 & 25.87347 \\
\hline ETA & .0000332485 & .000501 & .003321 & 0.010012 \\
\hline ROAE & .000544515 & .000460 & .000382 & 1.425434 \\
\hline COMM & .00208044 & .005369 & .016981 & 0.122516 \\
\hline QUOT & .0647023 & .062147 & .027051 & 2.391862 \\
\hline \multicolumn{5}{|l|}{1994} \\
\hline "FRA & $\begin{array}{l}.722489 \\
\end{array}$ & .741347 & .031735 & 22.76631 \\
\hline GER & .795564 & .815620 & .029239 & 27.209 \\
\hline ITA & .644545 & .665026 & .040140 & 16.05742 \\
\hline SPA & .654217 & .672066 & .032637 & 20.04526 \\
\hline UK & .785788 & .816669 & .029793 & 26.37492 \\
\hline ETA & .00132317 & .001818 & .002383 & 0.555254 \\
\hline ROAE & .000295890 & .000326 & .000575 & 0.514591 \\
\hline COMM & .00531899 & .011047 & .013562 & 0.392198 \\
\hline QUOT & .030135 & .032408 & .017517 & 1.720329 \\
\hline \multicolumn{5}{|l|}{1995} \\
\hline FRA & .643098 & .681423 & .040642 & 15.82348 \\
\hline GER & .754802 & .790288 & .030779 & 24.52328 \\
\hline ITA & .555382 & .598257 & .051829 & 10.71566 \\
\hline SPA & .585460 & .620156 & .040030 & 14.62553 \\
\hline UK & .731742 & .770682 & .038527 & 18.99297 \\
\hline ETA & -.00203572 & -.001273 & .002980 & -0.68313 \\
\hline ROAE & .00131381 & .001092 & .000790 & 1.663051 \\
\hline COMM & -.0033813 & -.001622 & .016602 & -0.20367 \\
\hline QUOT & .058225 & .057351 & .025906 & 2.247549 \\
\hline \multicolumn{5}{|l|}{1996} \\
\hline $\begin{array}{l}\text { FRA } \\
\end{array}$ & .610190 & .662319 & .042511 & 14.3537 \\
\hline GER & .719010 & .771952 & .037906 & 18.96824 \\
\hline ITA & .481954 & .551079 & .062123 & 7.758061 \\
\hline SPA & .518734 & .572392 & .044392 & 11.6853 \\
\hline UK & .783748 & .825845 & .029934 & 26.18253 \\
\hline ETA & .00562716 & .004095 & .003039 & 1.851649 \\
\hline ROAE & -.00011383 & -.000241 & .001016 & -0.11204 \\
\hline COMM & .00469199 & .004730 & .017498 & 0.268144 \\
\hline QUOT & .053910 & .053397 & .025292 & 2.131504 \\
\hline
\end{tabular}




\section{References}

Atkinson S. and P. Wilson, 1995, Comparing Mean Efficiency and Productivity Scores from Small Samples: a Bootstrap Methodology, Journal of Productivity Analysis, 6, 137-152.

Banca d'Italia, 1998, Annual Report.

Banker R.D., Charnes A. and W.W. Cooper, 1984, Some Models for Estimating Technical and Scale Efficiency in Data Envelopment Analysis, Management Science, 30,10781092.

Berg S.A., Førsund F.R., Hjalmarsson L. and M. Suominen, 1993, Bank Efficiency in the Nordic Countries, Journal of Banking and Finance, 17, 371-388.

Berger A. N. and D.B. Humphrey, 1997, Efficiency of Financial Institutions: International Survey and Directions for Future Research, European Journal of Operational Research, $98,175-212$.

Berger A.N., Hancock D. and D.B. Humphrey, 1993, Bank Efficiency Derived From the Profit Function, Journal of Banking and Finance, 17, 317-347.

Bhattacharyya A., Lovell C.A.K. and P. Sahay, 1997, The Impact of Liberalisation on the Productive Efficiency of Indian Commercial Banks' European Journal of Operational Research, 332-345.

Carbo, S., Gardener E.P.M. and J. Williams, 1999, 'Efficiency and Technical Change in the European Savings Bank Sector', paper presented at the Annual Seminar of the European Association of University Teachers of Banking and Finance (Lisbon, 2-3 September 1999).

Charnes A., Cooper W.W. and E. Rhodes, 1978, Measuring the Efficiency of DecisionMaking Units, European Journal of Operational Research, 2, 429 - 444.

Coelli T., Prasada Rao D.S. and G. E. Battese, 1998, An Introduction to Efficiency and Productivity Analysis, Kluwer Academic Publishers. 
Deprins D. and L. Simar, 1989, Estimating Technical Inefficiencies with Corrections for Environmental Conditions with and Application to Railways Companies, Annals of Public and Co-operative Economics, 60, 1 (Jan-Mar) 81-102.

Dietsch M. and L. Weill, 1998, Banking Efficiency and European Integration: Productivity, Cost and Profit Approaches, paper presented at the $21^{\text {st }}$ Colloquium of the SUERF (Frankfurt, 15 -17 October 1998).

Efron B., 1979, Bootstrap Methods: Another look at the Jackknife, Annals of Statistics, 7, 126.

European Commission, 1996, The Impact and Effectiveness of the Single Market, Communication to the European Parliament and Council (30 October 1996).

European Commission, 1997, Credit Institutions and Banking, Volume 4, Subseries II, Impact on Services, The Single Market Review (Kogan Page, London).

European Commission, 1997, The European Union: key figures, EUROSTAT (Brussels).

Farrell M. J., 1957, The Measurement of Productive Efficiency, Journal of Royal Statistical Society, 120, Sec. A, 253-281.

Ferrier G.D. and J.G. Hirschberg, 1995, Bootstrapping Confidence Intervals for Linear Programming Efficiency Scores: With an Illustration Using Italian Banking Data, Journal of Productivity Analysis, 8, 19-33.

Ferrier G.D. and V. Valdmanis, 1996, Rural Hospital Performance and its Correlates, Journal of Productivity Analysis, 7, (1), 63-80.

Fried H.O., Schmidt S.S. and S. Yaisawarng, 1995, Incorporating the Operating Environment into a Measure of Technical Efficiency, mimeo, (Union College, Schenecdaty).

Grosskopf S., 1996, Statistical Inference and Non-Parametric Efficiency: A Selective Survey, Journal of Productivity Analysis, 7, 161-176. 
Lovell C.A.K., 1993, Production Frontiers and Productive Efficiency, in Fried H.O., C.A.K. Lovell and S.S. Schmidt, eds., The Measurement of Productive Efficiency: Techniques and Applications (Oxford University Press, UK).

Lovell C.A.K., Walters L.C. and L. L. Wood, 1995, Stratified Models of Education Production Using Modified DEA and Regression Analysis, in Charnes A., Cooper W.W. Lewin A.Y. and L.M. Seiford, eds., Data Envelopment Analysis: Theory, Methodologies and Applications, Boston, Kluwer, 329-352.

Mester L.J., 1996, A Study of Bank Efficiency Taking into Account Risk-Preferences, Journal of Banking and Finance, 20, 389 - 405.

Molyneux P., Altunbas Y. and E.P.M. Gardener, 1996, Efficiency in European Banking, John Wiley \& Sons (Chichester, England).

Pastor J.M., Pérez F. and J. Quesada, 1995, Efficiency Analysis in Banking Firms: An International Comparison, WP-EC 95-18 (Istituto Valenciano de Investigaciones Economicas, Valencia, Spain).

Pastor J.T., Lozano A. and J.M. Pastor, 1997, Efficiency of European Banking Systems: A Correction by Environmental Variables, WP-EC 97-12 (Istituto Valenciano de Investigaciones Economicas, Valencia, Spain).

Resti A., 1997, Evaluating the Cost-Efficiency of the Italian Banking System: What can be Learned from the Joined Application of Parametric and Non-parametric Techniques, Journal of Banking and Finance, 2, 221-250.

Rouse P., 1996, Alternative Approaches to the Treatment of Environmental Factors in DEA: An Evaluation, Working paper (University of Auckland).

Seiford L.M., 1996, Data Envelopment Analysis: The evolution of the State of the Art (19781995), Journal of Productivity Analysis, 7, 99-138. 
Simar L, C.A.K. Lovell and P. Vanden Eeckaut, 1994, Stochastic Frontiers Incorporating Exogenous Influences on Efficiency, Discussion paper 9403 (Institut de Statistique, Université Catholique de Louvain, Belgium).

Simar L., 1992, Estimating Efficiency from Frontier Models with Panel Data: A Comparison of Parametric, Non-Parametric and Semi-Parametric Methods with Bootstrapping, Journal of Productivity Analysis, 3, 1/2, 171-191.

Simar L. and P. Wilson, 1995, Sensitivity Analysis of Efficiency Scores: How to Bootstrap in Non-parametric Frontier Models, Discussion paper 9503 (Institut de Statistique, Université Catholique de Louvain, Belgium).

Xue M. and P.T. Harker, 1999, Overcoming the Inherent Dependency of DEA Efficiency Scores: A Bootstrap Approach, Working paper $99-17$ (Financial Institution Center, The Wharton School, University of Pennsylvania). 
Table 1: Descriptive Statistics

\begin{tabular}{|c|c|c|c|c|c|c|c|c|}
\hline \multirow[b]{2}{*}{ COUNTRY } & & \multicolumn{7}{|c|}{ Size (total assets) in mil ECU, 1997} \\
\hline & $\begin{array}{c}\text { N. OF } \\
\text { BANKS }\end{array}$ & MEAN & MED. & ST.DEV. & MIN & MAX & Q1 & Q3 \\
\hline France & 112 & 14657 & 3890 & 43014 & 1585 & 310669 & 2906 & 6448 \\
\hline Germany & 112 & 16562 & 4660 & 45104 & 2560 & 376349 & 3230 & 9390 \\
\hline Italy & 116 & 9926 & 2567 & 19416 & 872 & 109076 & 1537 & 7071 \\
\hline Spain & 116 & 5962 & 1784 & 13190 & 283 & 81986 & 782 & 4245 \\
\hline U.K. & 74 & 21919 & 2158 & 53227 & 46 & 335632 & 321 & 16795 \\
\hline Euro5 & 530 & 13136 & 3264 & 36785 & 46 & 376349 & 1719 & 7062 \\
\hline $\begin{array}{l}\text { BANK } \\
\text { TYPE }\end{array}$ & $\begin{array}{c}\text { N. OF } \\
\text { BANKS }\end{array}$ & MEAN & MED. & ST.DEV. & MIN & MAX & Q1 & Q3 \\
\hline Commercial & 155 & 30367 & 5983 & 61748 & 312 & 376349 & 2172 & 24798 \\
\hline $\begin{array}{l}\text { Savings \& } \\
\text { Others }\end{array}$ & 375 & 6014 & 3037 & 13041 & 46 & 170432 & 1512 & 5359 \\
\hline
\end{tabular}


Table 2: Euro5 (DEA Efficiency Estimates)

\begin{tabular}{|c|c|c|c|c|c|c|c|c|c|c|c|c|c|c|c|}
\hline \multirow{2}{*}{\multicolumn{6}{|c|}{ CONSTANT RETURNS TO SCALE }} & \multicolumn{10}{|c|}{ VARIABLE RETURNS TO SCALE } \\
\hline & & & & & & \multicolumn{5}{|c|}{ INPUT BASED } & \multicolumn{5}{|c|}{ OUTPUT BASED } \\
\hline & Mean & Med. & St. D. & Q1 & Q3 & Mean & Med. & St. D. & Q1 & Q3 & Mean & Med. & St. D. & Q1 & Q3 \\
\hline $\begin{array}{c}1993 \\
(470)\end{array}$ & 0.591 & 0.571 & 0.125 & 0.507 & 0.648 & \begin{tabular}{|l|}
0.619 \\
\end{tabular} & 0.595 & 0.143 & 0.516 & 0.694 & 0.624 & 0.597 & 0.144 & 0.522 & 0.701 \\
\hline $\begin{array}{c}1994 \\
(484)\end{array}$ & 0.634 & 0.616 & 0.111 & 0.552 & 0.700 & 0.651 & 0.631 & 0.125 & 0.558 & 0.719 & 0.654 & 0.632 & 0.126 & 0.562 & 0.720 \\
\hline $\begin{array}{c}1995 \\
(483)\end{array}$ & 0.567 & 0.547 & 0.106 & 93 & 0.634 & 0.601 & 0.570 & 0.133 & 0.508 & 0.671 & 0.609 & 0.585 & 0.134 & 0.508 & 0.679 \\
\hline $\begin{array}{c}1996 \\
(499)\end{array}$ & 0.602 & 0.569 & 0.137 & 0.496 & 0.670 & 0.630 & 0.585 & 0.151 & 0.520 & 0.702 & 0.635 & 0.593 & 0.153 & 0.522 & 0.726 \\
\hline $\begin{array}{c}1997 \\
(424)\end{array}$ & 0.649 & 0.626 & 0.125 & 0.560 & 0.716 & 0.682 & 0.655 & 0.134 & 0.591 & 0.753 & 0.690 & 0.667 & 0.132 & 0.596 & 0.765 \\
\hline
\end{tabular}

Note: The numbers in brackets refer to the number of observations. 
Table 3: DEA Efficiency Estimates (VRS - Input Based)

\begin{tabular}{c|c|c|c|c|c|c|c|c|c|c}
\hline \hline & \multicolumn{2}{|c|}{ France } & \multicolumn{2}{c|}{ Germany } & \multicolumn{2}{c|}{ Italy } & \multicolumn{2}{c|}{ Spain } & \multicolumn{2}{c}{ UK } \\
\hline \hline & Mean & St. D. & Mean & St. D. & Mean & St. D. & Mean & St. D. & Mean & St. D. \\
\hline \hline 1993 & 0.607 & 0.179 & 0.697 & 0.132 & 0.558 & 0.080 & 0.534 & 0.096 & 0.725 & 0.108 \\
\hline 1994 & 0.648 & 0.144 & 0.725 & 0.109 & 0.567 & 0.064 & 0.590 & 0.081 & 0.763 & 0.089 \\
\hline 1995 & 0.589 & 0.139 & 0.690 & 0.121 & 0.502 & 0.066 & 0.540 & 0.079 & 0.772 & 0.096 \\
\hline 1996 & 0.620 & 0.136 & 0.724 & 0.128 & 0.508 & 0.059 & 0.544 & 0.071 & 0.829 & 0.108 \\
\hline 1997 & 0.653 & 0.121 & 0.762 & 0.118 & 0.553 & 0.063 & 0.644 & 0.074 & 0.819 & 0.114 \\
\hline \hline
\end{tabular}


Table 4: Composition of the Efficient Frontier (VRS)

\begin{tabular}{l|c|c|c|c|c}
\hline \hline N. OF EFFICIENT BANKS & 1993 & 1994 & 1995 & 1996 & 1997 \\
\hline \hline FRANCE & & & & & \\
\hline GERMANY & 8 & 7 & 4 & 6 & 4 \\
\hline ITALY & 7 & 8 & 7 & 8 & 7 \\
\hline SPAIN & - & - & - & - & - \\
\hline UK & 1 & - & - & 1 & 1 \\
\hline \hline EURO5 & 4 & 3 & 2 & 6 & 6 \\
\hline \hline
\end{tabular}


Table 5: Tobit Censored Regression 1997 Data

\begin{tabular}{|l|c|c|c|c|}
\hline & $\hat{\beta}_{j}$ & Std. Error & t value & $\operatorname{Pr}(>|t|)$ \\
\hline FRA & .622509 & .017445 & 35.6843 & .0000 \\
\hline GER & .732809 & .014637 & 50.0659 & .0000 \\
\hline ITA & .500420 & .022235 & 22.5055 & .0000 \\
\hline SPA & .580022 & .021130 & 27.4496 & .0000 \\
\hline UK & .791588 & .019954 & 39.6707 & .0000 \\
\hline ETA & $.357723 \mathrm{E}-02$ & $.222236 \mathrm{E}-02$ & 1.60965 & .1075 \\
\hline ROAE & $.231090 \mathrm{E}-02$ & $.641920 \mathrm{E}-03$ & 3.59998 & .0003 \\
\hline COMM & .018185 & .012959 & 1.40322 & .1606 \\
\hline QUOT & .037875 & .015998 & 2.36745 & .0179 \\
\hline
\end{tabular}

NOTE: FRA= France; GER= Germany; ITA= Italy; SPA= Spain; UK= United Kingdom; ETA= Equity/Total Assets; ROAE= Return on Average Equity; COMM= Commercial Banks; QUOT= Banks listed on the Stock Exchange. 
Table 6: Bootstrap Tobit Censored Regression with C = 1000 Samples (1997 Data)

\begin{tabular}{|l|c|c|c|c|}
\hline & $\hat{\beta}_{j}$ & $\bar{\beta}_{j}$ & $\hat{s} e_{100}\left(\hat{\beta}_{j}\right)$ & t value \\
\hline FRA & .622509 & .666153 & .041083 & \\
\hline GER & .732809 & .769757 & .031524 & 23.15247 \\
\hline ITA & .500420 & .565224 & .071447 & 7.004073 \\
\hline SPA & .580022 & .622903 & .039952 & 14.51797 \\
\hline UK & .791588 & .811953 & .025614 & 30.90451 \\
\hline ETA & .003577 & .004325 & .002895 & 1.235579 \\
\hline ROAE & .002310 & .001906 & .01010 & 0.228713 \\
\hline COMM & .018185 & .020081 & .015789 & 1.151751 \\
\hline QUOT & .037875 & .034222 & .026283 & 1.441046 \\
\hline
\end{tabular}

NOTE: FRA= France; GER= Germany; ITA= Italy; SPA= Spain; UK= United Kingdom; ETA= Equity/Total Assets; ROAE= Return on Average Equity; COMM= Commercial Banks; QUOT= Banks listed on the Stock Exchange. 
Figure 1: Frequency Distribution of Average Efficiency Scores

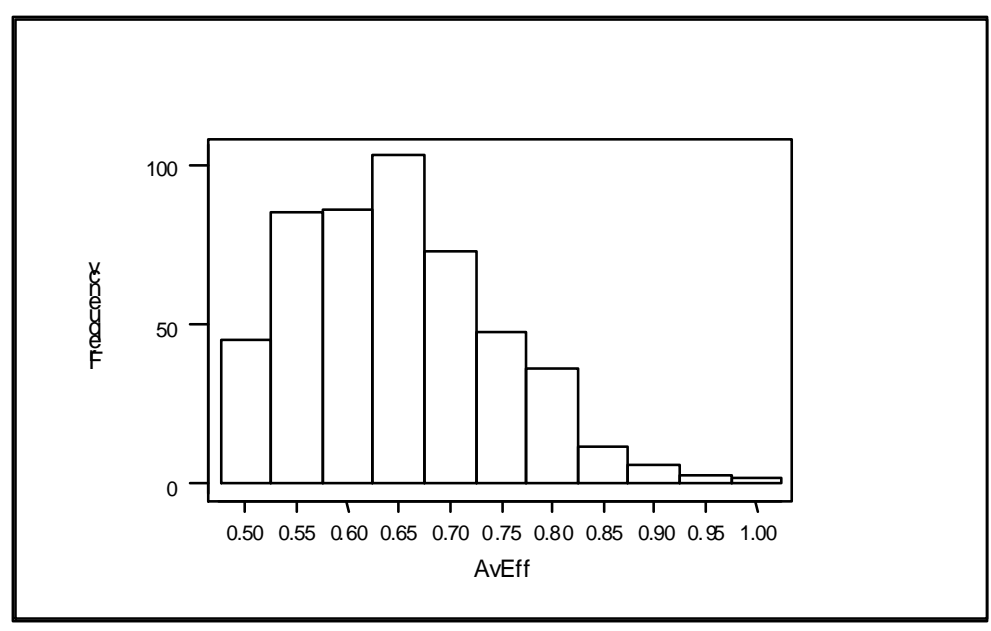


Figure 2: DEA Efficiency Scores

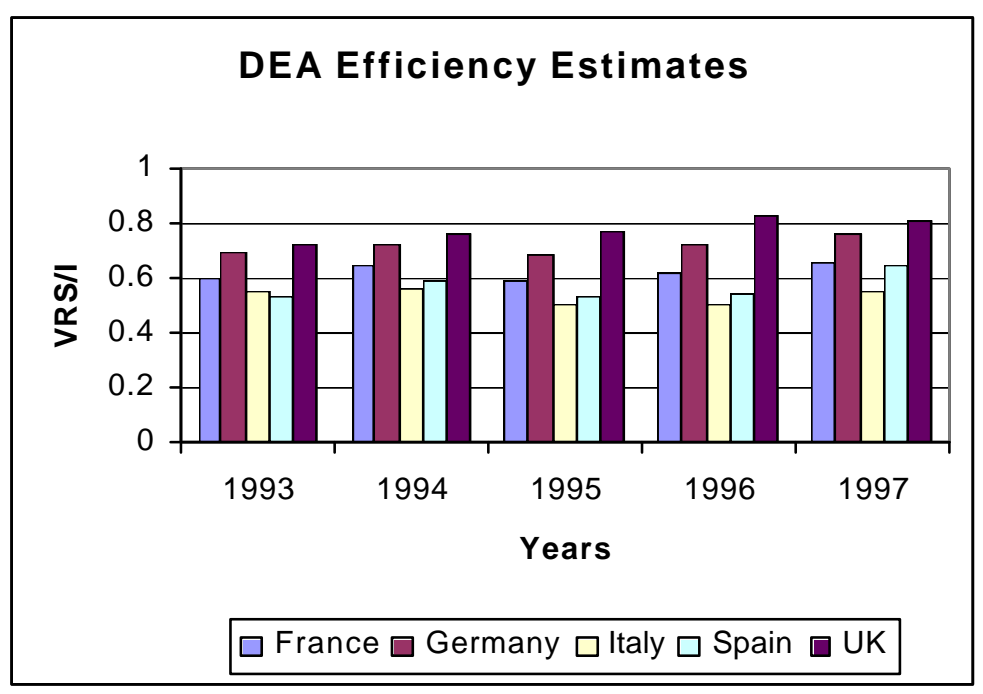

